\title{
CLASSIC ABDOMINOPLASTY: A NEW APPROACH TO THE CORRECTION OF THE ABDOMINAL WALL DEFORMITY IN PATIENTS WITH BLADDER EXSTROPHY - A CASE REPORT
}

\author{
doi: $10.1590 / \mathbf{S 1 8 0 7 - 5 9 3 2 2 0 0 9 0 0 0 9 0 0 0 1 6}$
}

Tatiana Moura, ${ }^{\mathrm{I} J o n a s}$ Eraldo de Lima Junior, ${ }^{\mathrm{I}}$ Eduardo Sakae, ${ }_{\mathrm{I}}^{\mathrm{F}}$ abio Aki, ${ }^{\mathrm{I}}$ Amilcar Martins Giron, ${ }^{\mathrm{II}}$ Marcus Castro Ferreira ${ }^{\mathrm{I}}$

\section{INTRODUCTION}

Classic bladder exstrophy is a rare congenital deformity, with an incidence that is estimated to be 3.3 per 100,000 infants born alive. ${ }^{1}$ The ratio between cases in males and females is $1: 1.5 .^{1-2}$ It is routinely diagnosed intrauterine during prenatal scans. This deformity is characterized by a lack of closing of the anterior bladder wall, absence of the infra-umbilical abdominal wall and pubic diastasis, with high rates of unfavorable evolution. ${ }^{3-4}$ These cases require precocious treatment because mortality rates reach $75 \%$ by fifteen years of age if not corrected surgically. ${ }^{5}$

The approach for surgical correction in these cases is a complex and controversial process that can be divided into three categories: physiologic function, cosmetic appearance and physical image, and social and psychological adaptation. To restore physiologic function to the bladder, the vesical wall is closed surgically, and a bilateral iliac osteotomy is created. ${ }^{6-7}$ This surgery is followed by treatments that are meant to promote urinary continence, which are frequently comprised by the construction of urinary reservoirs and conduits for intermittent catheterization. ${ }^{8-13}$

To restore cosmetic appearance and physical image, several surgical techniques can be used. The approach must be individualized for each case according to existing deformities and the surgical procedures that the patient has already undergone. ${ }^{14-15}$ Some of the techniques that are used for this step include the following: neo-phalloplasty, lower

\footnotetext{
${ }^{\text {I }}$ Disciplina de Cirurgia Plástica e Queimaduras, Hospital das Clínicas da Faculdade de Medicina da Universidade de São Paulo - São Paulo/SP, Brazil. "Disciplina de Urologia, Hospital das Clínicas da Faculdade de Medicina da Universidade de São Paulo - São Paulo/SP, Brazil.

Email: jonas_med@hotmail.com

Tel: 55113069.3363
}

rotation muscle flap from the rectus abdominis muscle for the filling of the pubic region, approximation of the labia majora with reconstruction of the cleft of Venus and correction of prior scars.

By describing the present case, we aim to suggest a new surgical approach, an abdominal dermolipectomy, for the correction of the cosmetic deformities after restoration of micturition.

\section{CASE DESCRIPTION}

A fourteen-year-old female patient was referred for correction of her abdominal deformity. The diagnosis of bladder exstrophy was made during routine prenatal scans, which were later confirmed at birth, and was located in the infra-umbilical region. At 22 days of life, she underwent a simple closing of the bladder and abdominal walls as well as a bilateral iliac osteotomy. Although the patient was meeting her psychological, neurological and motor developmental milestones, she presented with urinary incontinence. At six years of age, she underwent a urethral reconstruction with a neosphincter. She had partial success in the restoration of urinary continence, although it was gradually lost. By the age of 12, she was incontinent again, and the best option was a bladder augmentation with the Mitrofanoff technique and intermittent catheterization (carried out in three-hour intervals), along with physical therapy to restore continence.

With the beginning of adolescence, the scars and abdominal defect from the prior surgeries became complaints that were related to body image. During preoperative evaluation, the patient presented with a middle non-aesthetic scar in the hypogastric region, skin excess in the epigastric region provoking an incurvation above the catheterization conduit (located midline, $25 \mathrm{~cm}$ above 
the vulva) and notable separation of the labia majora. Considering the excess of skin in the epigastric region, the presence of an inferior aponeurosis (with no clinically obvious hernia) and the presence of the catheterization conduit midline, an abdominal dermolipectomy was suggested as the best therapeutic option, accompanied by the externalization of the conduit for catheterization by neo-umbilicoplasty (Figure 1). After the abdominal incision was placed in the transition between the hypogastric region and the pubis, extending laterally to the anterior superior iliac spines, the skin abdominal flap was detached at the suprafascial level onto the epigastrium. For the exteriorization of the bladder catheterization conduit, a half-moon-shaped opening in a transverse orientation was placed in the abdominal flap in the location corresponding to the neo-umbilicus. Such a maneuver was possible in the present case because the patient had the exteriorization of this conduit midline, approximately two centimeters below the adequate position for the umbilical scar. Through a delicate dissection of the borders of the urinary derivation,

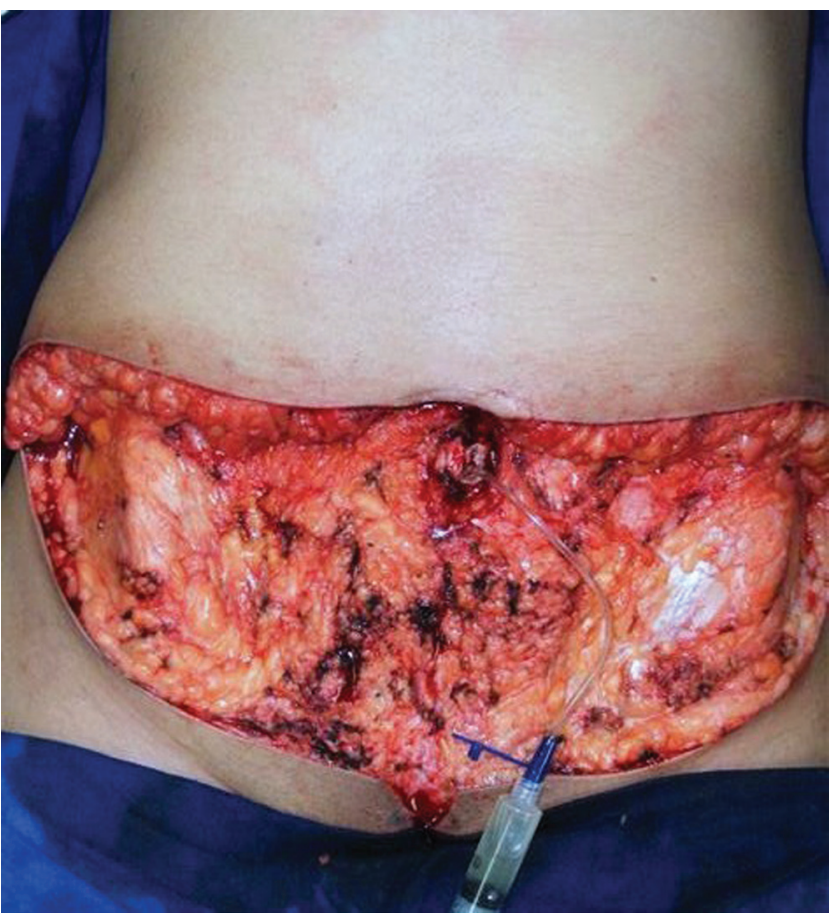

Figure 1 - Catheter located in the vesical conduct, showing the localization of the neoumbilicus

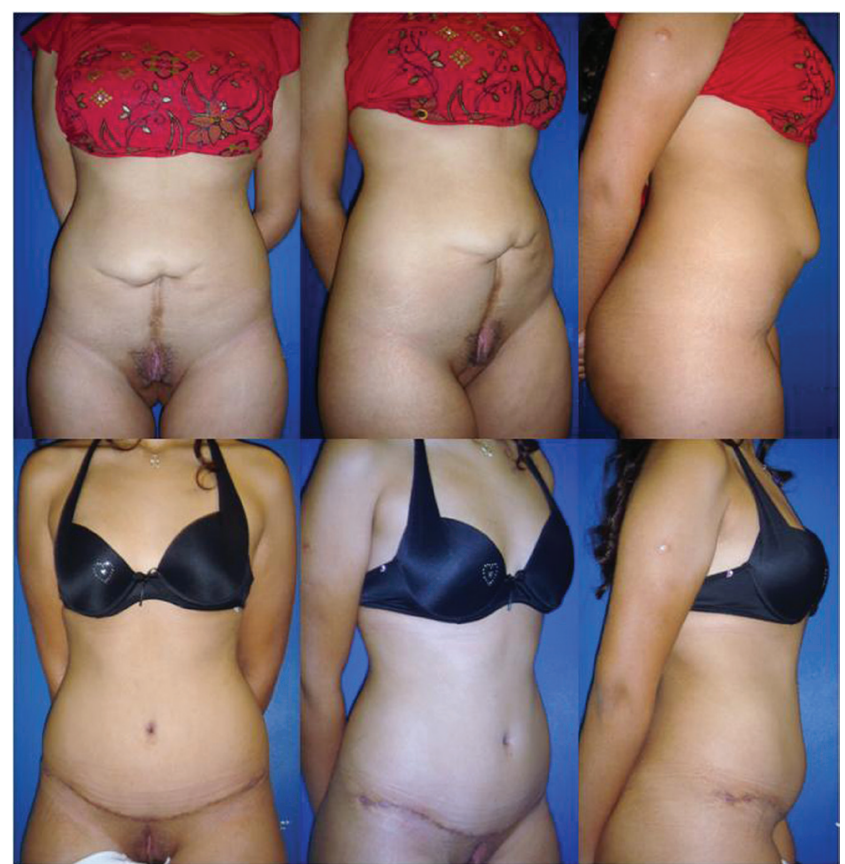

Figure 2 - Above - pre operative. Below - post operative

it was possible to move it 1.5 centimeters upwards, thus allowing its fixation with mononylon thread stitches in a more appropriate position by anchoring the skin abdominal flap to the aponeurosis around the stoma. After advancing the abdominal flap downward, the skin excess was removed. Finally, the layers of the abdominal wall were closed (Figure 2 ). The post-operative evolution of the procedure was satisfactory, without any complications.

\section{DISCUSSION}

Patients with bladder exstrophy have multiple hospital admissions and require repeated surgical procedures and specialized care, including repeat catheterization, as part of their daily lives. This situation often makes patients introspective and dissatisfied with their physical image, which, in turn, makes it difficult for them to integrate psychologically and socially. With this case report, we aim to report the use of an established and optimized surgical technique for the correction of the abdominal walls of these patients, thereby improving their cosmetic appearance.

\section{REFERENCES}

1. Valioulis I, Levard G, Lottmann H, Hameury F, Cendron J. A rare complex bladder exstrophy variant. BJU Int. 2000;86:398-400.

2. Marshall VF, Muecke EC. Variations in exstrophy of the bladder. J Urol. 1962;88:766-96.
3. Turner WR Jr, Ransley PG, Bloom DA, Williams DI. Variants of the exstrophic complex. Urol Clin North Am. 1980;7:493-501.

4. Mildenberger H, Kluth D, Dziuba M. Embryology of bladder exstrophy. J Pediatr Surg. 1988;23:166-70. 
5. Vermeij-Keers C, Hartwig NG, van der Werff JF. Embryonic development of the ventral body wall and its congenital malformations. Semin Pediatr Surg. 1996;5:82-9.

6. Muecke EC, Marshall VF. Subsymphyseal epispadias in the female patient. J Urol. 1968;99:622-8.

7. Mathews R, Sponseller PD, Jeffs RD, Gearhart JP. Bladder neck reconstruction in classic bladder exstrophy: the role of osteotomy in the development of continence. BJU Int. 2000;85:498-500.

8. Hejtmancik JH, King WB, Magid MA. Pseudo-exstrophy of bladder. J Urol. 1954;72:829-32.

9. Narasimharao KL, Pathak IC. Superior vesical fistula: a rare exstrophic variant. J Urol. 1983,129:138-9.

10. Grady RW, Mitchell ME. Complete primary repair of exstrophy. J Urol. 1999;162:1415-20.
11. Gearhart JP, Jeffs RD. State-of-the-art reconstructive surgery for bladder exstrophy at the Johns Hopkins Hospital. Am J Dis Child. 1989;143:1475-8

12. Borer JG, Gargollo PC, Hendren WH, Diamond DA, Peters CA, Atala A. Early outcome following complete primary repair of bladder exstrophy in the newborn. J Urol. 2005 Oct;174(4 Pt 2):1674-8; discussion 1678-9.

13. Leadbetter GW. Surgical correction of total urinary incontinence. J Urol. 1964;91:261-6.

14. Yerkes EB, Adams MC, Rink RC, Pope JC IV, Brock JW 3rd. How well do patients with exstrophy actually void? J Urol. 2000;164:1044-7.

15. Woodhouse CR. The fate of the abnormal bladder in adolescence. $\mathrm{J}$ Urol. 2001;166:2396-400. 